Revue d'histoire de l'Amérique française

RAS REVUE D.HISTOIRE DE L'AMÉRIQUE FRANÇAISE

\title{
Le gouvernement responsable 1848-1948 (suite)
}

\section{Jean-Pierre Houle}

Volume 1, numéro 3, décembre 1947

URI : https://id.erudit.org/iderudit/801385ar

DOI : https://doi.org/10.7202/801385ar

Aller au sommaire du numéro

Éditeur(s)

Institut d'histoire de l'Amérique française

ISSN

0035-2357 (imprimé)

1492-1383 (numérique)

Découvrir la revue

Citer cet article

Houle, J.-P. (1947). Le gouvernement responsable 1848-1948 (suite). Revue d'histoire de l'Amérique française, 1(3), 342-345.

https://doi.org/10.7202/801385ar d'utilisation que vous pouvez consulter en ligne.

https://apropos.erudit.org/fr/usagers/politique-dutilisation/ 


\title{
LE GOUVERNEMENT RESPONSABLE 1 \\ $1848-1948$
}

\author{
II \\ L'INSTRUMENT DE LIBERATION
}

( In 1791 parliament under leadership of Pitt's ministry framed a new government for Canada. The debate on the bill shows conclusively that the desire was to give to Canada the same kind of government which England had, and then can be no question but that this was honestly intended. And yet no responsible ministry was granted nor ever proposed, and the foundation was laid for the later Canadian rebellion which opened a new era in British colonial government. ")

(George Burton Adams: «Constitutional History of England ))

(" This is not a time to make hazardous experiments ). Mr. Pitt, in 1792.

Si l'on veut bien, avant d'attaquer cet article, relire le texte cité en exergue, on reconnaîtra l'exactitude de la conclusion inscrite dans notre précédente étude. Il est donc indiscutable qu'en 1791, le gouverp. 166-70.

1. Voir 1er article, Revue d'Histoire de l'Amérique fransaise (septembre 1947), 
nement métropolitain nous dotait du régime parlementaire sans toutefois nous remettre en même temps l'instrument capable d'assurer le développement normal de ce régime politique. Cet instrument c'est le système de gouvernement par un cabinet responsable au corps législatif élu par la nation. La définition n'est peut-être pas élégante, mais elle est précise. Nous répétons qu'il n'y a, dans ce refus du gouvernement impérial, aucun machiavélisme. Et si ce n'est pas le lieu de retracer l'évolution constitutionnelle de l'Angleterre, rappelons tout simplement ceci qui nous paraît indispensable pour une meilleure intelligence de la situation au Canada, au lendemain de 1791. Nous devons dater de la formation du ministère Pitt, décembre $\cdot 1783$, l'existence, au sens plein du mot, du régime parlementaire en Angleterre. Nous pouvons dès ce moment parler d'un cabinet, mais à la condition de ne pas prêter à ce terme plus de signification qu'il n'en avait à l'époque. Or il est certain que l'on n'avait pas une idée très précise du système de gouvernement par cabinet, système qui commande la responsabilité ministérielle. En fait, on mettra encore pas moins de vingt-cinq ans à parfaire le mécanisme et même on n'en verra fonctionner, sans grincement, tous les rouages qu'à l'occasion du débat, 1831-32, autour de la réforme électorale. Qu'est-ce à dire ? Que l'on peut accepter le mot de Adams: " that the desire was to give to Canada the same kind of government which England had........ ) et ce régime politique-là, où il est né, ne comportait pas encore pratique normale, régulière, de la responsabilité ministérielle.

Nous ne croyons pas franchir les limites permises au commentateur de notre histoire constitutionnelle, en affirmant que les luttes parlementaires livrées dans le Bas-Canada, dans la 1ère moitié du XIXe siècle, ont contribué au développement du système parlementaire anglais, et en reconnaissant que nos premiers hommes politiques ont manifesté un singulier don de vue.

Pour les parlementaires anglais comme pour les nôtres, l'objectif était de trouver un instrument de libération politique et la responsabilité ministérielle n'est pas autre chose; que si, dans le Bas-Canada, l'instrument devait servir, du moins dans la pensée de ceux qui entendaient le manier, à une libération nationale, cela ne change rien à sa fonction première. Instrument de libération politique, c'est ce qui explique 
et justifie, croyons-nous, que nos parlementaires aient tenté, tout d'abord, d'obtenir la responsabilité ministérielle par le vote et la disposition des subsides.

\section{III}

\section{PRÉLIMIN AIRES}

Il est sans doute opportun de rappeler que c'est l'actif et intelligent Pierre Bédard, qui le premier, a traité directement du gouvernement responsable, soit dans Le Canadien, soit à l'Assemblée elle-même, notamment lors du débat sur l'adresse en réponse au discours du trône, à l'ouverture de la session, le 9 avril 1809 . Bédard a montré une compréhension des institutions britanniques qui le place bien en avant de son temps. Nous croyons même que le discours qu'il a prononcé en cette occasion, pour produire tout son effet, aurait dû être donné aux Communes anglaises. En effet, Bédard, par des rapprochements subtils et une dialectique très serrée, définit ce qu'est l'opposition, rouage essentiel du régime parlementaire, et il en arrive à poser le principe même de la responsabilité ministérielle. Il faudra attendre LaFontaine pour retrouver une logique aussi vigoureuse et une pareille lucidité. La conclusion du discours de Bédard peut se résumer ainsi: la situation du gouvernement est constitutionnellement absurde puisque le ministère a joué le rôle de l'opposition. Vèrs 1815, le gouvernement métropolitain a parfaitement saisi le jeu de la majorité française à l'Assemblée législative: ce que celle-ci veut obtenir, c'est le gouvernement responsable dont le principe était inclus dans le régime établi en 1791. Mais le gouvernement impérial a été effrayé d'une trop grande logique qui tient absolument à dégager et à formuler la conclusion contenue dans les prémisses; et c'est pourquoi, malgré quelques concessions tardives, il s'en tiendra à une politique d'expédients. Accorder le gouvernement responsable, instrument de libération, c'eût été admettre, pour un avenir plus ou moins rapproché, la fin de l'époque coloniale. En possession de cet instrument, les colonies ne tarderaient pas à travailler à leur indépendance.

Devons-nous nous excuser d'avoir reporté à un troisième et dernier article, l'étude des principales étapes qui conduiront à la reconnais- 
sance du gouvernement responsable ? Nous avons jugé utiles ces quelques précisions qui complètent notre première étude et qui nous permettront d'aborder en toute sécurité l'année 1841.

Jean-Pierre Houle

professeur a l'Institut d'Histoire, Faculte des Lettres, Université de Montréal. 